\title{
ESTÁNDARES DE PRUEBA Y JUICIOS POR VIOLACIONES A LOS DERECHOS HUMANOS*
}

\author{
Rodrigo Coloma Correa**
}

\begin{abstract}
RESUMEN
A partir del análisis de las implicaciones que trae consigo la definición de estándares de prueba en un sistema jurídico - ello, en cuanto determinarán cómo debieran ser distribuidos entre las partes los posibles errores epistémicos en los cuales los jueces pudieren incurrir-, se sugiere uno específico para ser utilizado en los juicios por violaciones a los derechos bumanos. Al estándar sugerido se le ha llamado de la preferencia de las buenas explicaciones no derrotadas, cuya fuerza radicaría en que tienen adecuada consideración las particularidades y las expectativas que se ciernen sobre el proceso de adjudicación que se lleva a cabo en el contexto de dicha clase de conflictos.
\end{abstract}

\section{ESTÁNDARES DE PRUEBA - VIOLACIONES A LOS DERECHOS HUMANOS - FUNCIONES DE LAS SENTENCIAS}

\section{Standards of proof and buman rights proceedings}

\begin{abstract}
Through the analysis of the consequences generated by the definition of standards of proof within a legal system -that determine how the possible epistemic errors in which judges may incur should be distributed among the parties-a specific standard of proof for proceedings on buman rights violations is proposed. This standard has been called preference of non-defeated good explanations, and its soundness lies in taking adequately into account both the particularities and the prospects involved in the process of adjudication that takes place in this type of disputes.
\end{abstract}

\section{STANDARDS OF PROOF - HUMAN RIGHTS VIOLATIONS - FUNCTIONS OF JUDGEMENTS}

* Una versión preliminar de este artículo fue presentada en el Seminario 3 de la Facultad de Derecho de la Universidad Alberto Hurtado, como también en las III Jornadas Argentino-Chilenas de Filosofía del Derecho efectuadas en la ciudad de Mendoza, en mayo de 2009. Agradezco las agudas observaciones que me fueron realizadas en ambos encuentros y la cuidada revisión del borrador de parte de Flavia Carbonell y de Héctor Hernández, las cuales me han ayudado a mejorar esta versión final. Las obscuridades y debilidades que aún persisten son atribuibles, en forma exclusiva, a mi persona.

** Abogado, Doctor en Derecho, Profesor adjunto de la Facultad de Derecho de la Universidad Alberto Hurtado, Santiago de Chile, rcoloma@uahurtado.cl

Artículo recibido el 10 de junio de 2009 y aceptado para su publicación por el Comité Editorial el 26 de octubre de 2009. 
- ¿Qué quieres de ese hombre? -preguntó de repente la nodriza.

- La verdad-respondió el general.

- Conoces muy bien la verdad.

-No la conozco - dijo él, en voz alta, sin preocuparse por el servicio, que habia interrumpido abajo la colocación de las flores y miraba bacia arriba. Volvieron a bajar la mirada inmediatamente, con un gesto mecánico, y continuaron con sus quehaceres-. La verdad es precisamente lo que no conozco.

-Pero conoces la realidad-observó la nodriza, con un tono agudo, casi agresivo.

- La realidad no es lo mismo que la verdad - respondió el general-. La realidad son sólo detalles. Ni siquiera Krisztina conocía la verdad. Quizás la sepa Konrád. Abora se la quitaré - dijo con mucha calma. ${ }^{1}$

\section{INTRODUCCIÓN}

$\mathrm{L}$ o que enseguida trataré tiene que ver con estándares de prueba y con juicios por violaciones a los derechos humanos. Ya que la combinación de ambas variables podría dar pie a la configuración de múltiples problemas y, por cierto, de otras tantas soluciones; intentaré precisar, desde ya, lo que haré a continuación. Mi intención es desarrollar una propuesta -de aquellas que los penalistas llamarían de lege ferenda-, que se hará cargo de la fijación, en términos abstractos, de la cantidad de verdad que sería razonable exigir para la condena de quienes estén siendo procesados por su presunta participación en violaciones a los derechos humanos. El estándar de prueba que sugeriré lo he llamado de la preferencia de las buenas explicaciones no derrotadas; el cual sería, por una parte, más débil que el que ordinariamente es identificado como propio de las causas penales y, por la otra, más exigente que aquel que habitualmente se declara aplicable para las causas civiles.

Como se extrae de lo recién dicho, mis pretensiones no pasarán por describir la manera en que los tribunales de hecho entienden que el estándar de prueba que estaría previsto para los juicios por violaciones a los derechos humanos, es (o no) superado en casos concretos. Así, el análisis que será realizado no se hará cargo, por ejemplo, de la corrección o incorrección de la forma en que los tribunales de justicia han operado históricamente, ni de asuntos tales como la viabilidad política de llevar adelante procesos por violaciones a los derechos humanos hasta las últimas consecuencias. $^{2}$ Tampoco se encuentra dentro de mis pretensiones clarificar los alcances

${ }^{1}$ Márai, S. El último encuentro. Salamandra, Barcelona, 1999, p. 67.

${ }^{2}$ En Chile, por ejemplo, se podría entender que los principales problemas que han debido afrontarse a raíz de los procesos seguidos por violaciones a los derechos humanos han tenido que ver con la determinación de la validez atribuida a normas dudosas que aspiran a regular estos casos (D.L. de Amnistía), como 
que pudieran derivarse de la aplicación de estándares de prueba tales como del más allá de toda duda razonable, del clara y convincentemente o del de la preponderancia de la prueba disponible.

La fuerza de dicha propuesta radica en que el estándar de prueba sugerido se haría cargo, adecuadamente, de los bienes que se encuentran en pugna cuando los jueces enfrentan el problema de decidir -bajo incertidumbre- si darán o no por probados ciertos hechos que se hacen aparecer como antecedente de algunas de las soluciones previstas en los sistemas jurídicos (básicamente bajo la forma de penas o de indemnizaciones de perjuicios). Asimismo, la propuesta asume de manera no ingenua, ni pesimista, las dificultades epistémicas a las cuales se ven expuestos los jueces a quienes se fuerza a elegir sólo una de las historias que han sido presentadas como solución al enigma que ha dado vida al litigio, desechando en consecuencia a las restantes en competencia.

El camino a seguir para tales fines será el siguiente: en primer lugar, se intentará explicar las razones que llevan a los sistemas jurídicos a instaurar estándares de prueba; luego, se explorarán razones para el uso de los estándares de prueba del más allá de toda duda razonable y de la preponderancia de la prueba disponible, propio de los asuntos penales y de los asuntos civiles; por último, se tratará de justificar por qué el estándar de prueba de la preferencia de las buenas explicaciones no derrotadas constituiría una vía adecuada para zanjar los problemas de distribución del error en juicios por violaciones a los derechos humanos.

\section{II. ¿PARA QUÉ ESTÁNDARES DE PRUEBa?}

Para entender las razones que llevan a la incorporación de estándares de prueba en los sistemas jurídicos, parece inevitable situarse en el contexto de la función de adjudicación, cuyo ejercicio -como se sabe- se encuentra reservado a los tribunales de justicia. Los estándares de prueba constituyen uno de los engranajes claves del proceso judicial que posibilitan a los jueces la elección justificada de un cierto curso de acción; ello sobre la base de que ciertas reglas de conducta que han sido reconocidas como pertenecientes al sistema jurídico respectivo habrían sido (o no habrían sido) violadas por uno o más de los habitantes de un determinado territorio. Tales normas a aplicar -usualmente calificadas como sustantivas, o siguiendo a H.L.A. Hart, como reglas primarias de obligación ${ }^{3}$ - presentan una estructura lógica que podría fácilmente ser reducida a la forma básica: "Si alguien hace (o no hace) $c$, entonces debe ser $p$ ". Esta manera de construir los enunciados jurídicos (o bien de reconstruirlos mediante proposiciones normativas)

también de interpretación de textos (¿desde cuándo empieza a operar la prescripción en caso de secuestros?). Sin embargo, y al igual que en casi cualquier clase de juicio, ha habido problemas en cuanto a la determinación de la prueba requerida para llegar a demostrar la culpabilidad de los acusados, cuestión para la cual la definición del estándar de prueba exigible pasa a ser relevante.

${ }^{3}$ Hart, H.L.A., El concepto de derecho. $2^{\text {a }}$ ed. Abeledo-Perrot, Buenos Aires, 1977, pp. 113 y ss. 
resulta adecuada para efectos de reforzar la función de orientación de comportamientos que de la gente se espera, pues supone que las cargas y beneficios indicados serán efectivamente impuestos sobre los individuos que hayan ejecutado u omitido realizar aquellas conductas a las que tales soluciones se encuentran conectadas. Esto, entonces, implicará prima facie que en el contexto de la adjudicación resultaría necesario que los jueces puedan llegar a determinar si una norma ha sido o no efectivamente violada, para el caso que de ello existieren sospechas razonablemente fundadas.

Lo expresado ha sido recurrentemente advertido por distintos autores. Como botón de muestra, Carlos Alchourrón y Eugenio Bulygin han señalado que: "Es importante subrayar que la norma del derecho penal estipula el deber de sentenciar a aquellos que han cometido homicidio y no a aquellos de los que el juez dice que han cometido homicidio". ${ }^{4}$ Mirjan Damaska, por su parte, ha señalado que: "uno de los presupuestos de trabajo de la práctica de adjudicación es que la verdad es en principio posible de descubrir, y que la precisión en el tratamiento de los hechos constituye una precondición para una decisión justa". Susan Haack, por último, ha planteado que: "La justicia, por supuesto, requiere de leyes justas y de la justa administración de dichas leyes; pero también requiere de verdad factual”. 6

La exigencia recién mencionada ha sido frecuentemente entendida en términos de que los jueces estarían obligados a hacer lo posible para llegar a desentrañar la verdad, lo que no implicará, por cierto, que deban efectivamente alcanzarla. ${ }^{7}$ En otras palabras, se espera de los jueces que hagan todo lo que esté de su parte para identificar correctamente a las personas que, por ejemplo, hayan cometido un hurto, o que hayan sido diligentes en el cuidado de sus hijos; ello por cuanto constituyen conductas a las que se pueden asociar determinadas consecuencias jurídicas. Para efectos de intentar hallar la verdad, los jueces se aprovecharán del rico -y, a veces, enrevesado- material que les es suministrado por las partes por vía de discursos de abogados, de declaraciones de testigos o de lectura de documentos, como también harán uso de un background de conocimientos acumulados, ya sea desde sus propias experiencias de vida o bien desde las reflexiones de terceros. Todo ello les ayudará a construir explicaciones que podrán llegar a ser reconocidas como representaciones plausibles acerca de cómo ha sido, cómo es o cómo llegará a ser el mundo.

Sin embargo, como se sabe, el asunto es bastante más espinoso que lo que, a primera vista, pudiera parecer. Esta búsqueda de la verdad llevará a los jueces y a las partes interesadas -más temprano que tarde- a golpearse de manera brutal con barreras de

${ }^{4}$ Alchourrón, C., Bulygin, E. "Los límites de la lógica y el razonamiento jurídico", en ID. Análisis lógico y derecho. Centro de Estudios Constitucionales, Madrid, 1991, p. 313.

5 Damaška, M. "Truth in adjudication”, en Hastings Law Journal 49, 1998, p. 289.

${ }^{6}$ Haack, Susan. "Truth and Justice, Inquiry and Advocacy, Science and Law”, en Ratio Juris, vol. 17, $\mathrm{N}^{\circ} 1$, March 2004, p. 15.

${ }^{7}$ Cfr. Celano, B. "Judicial decision and truth. Some remarks", en Gianformaggio, Letizia; Paulson, Stanley. Cognition and Interpretation of Law. G. Giappichelli, Torino, 1995, p. 145. 
naturaleza epistémica cuasi infranqueables, las que súbitamente les harán recordar que el conocimiento humano dista mucho de ser seguro. Configurarían tales barreras, por cierto, la inseguridad y las lagunas que aquejan al cúmulo de datos disponible, como también la precariedad de las generalizaciones a las que se recurrirá para llevar a cabo aquellas inferencias que serían indispensables llegar a aprehender lo desconocido.

Cuando se alude a la fragilidad del conocimiento, difícil resulta resistirse a reproducir las conocidas y, probablemente, exageradas palabras con las que Nietzsche quiso dar cuenta de ello. Decía Nietzsche: "En un rincón apartado del universo, donde brillan innumerables sistemas solares, hubo una vez un astro en el cual unos animales inteligentes inventaron el conocimiento. Fue el minuto más soberbio y falaz de la «historia universal», pero sólo un minuto. Después de unos pocos respiros de la naturaleza es astro se heló, y los animales inteligentes debieron morir. Alguien podría haber inventado una fábula así y sin embargo no habría ilustrado lo suficiente el estado lamentable, sombrío y fugaz; carente de sentido y caprichoso en que se muestra el intelecto humano en la naturaleza". 8

Si lo sombrío de este panorama -que, por lo demás, atraviesa distintas esferas de nuestras vidas- no nos llevare a abandonarnos a un escepticismo radical, seguramente nuestras pretensiones serán morigeradas, por vía de reconocer que el conocimiento que podremos producir, aun cuando útil, será falible e interino, esto es, mientras no aparezca nada mejor. Este es el camino, por ejemplo, asumido por comunidades especialmente reputadas en el campo científico, como es el caso de los físicos, los biólogos o los químicos. En las disciplinas prácticas, como es el caso del derecho -del cual se esperan sobre todo respuestas a preguntas acuciantes de la clase del ¿qué se debe hacer con Gestas que ha sido acusado de haber cometido un hurto? o ¿con quién debe vivir la pequeña Eufrasia, cuya tuición es reclamada tanto por Fantine como por Tholomyes?-, el conocimiento no podrá permanecer mucho tiempo bajo el estatus de interinidad. No asumir ello implicaría que el derecho siempre llegará tarde a todas partes. En vista de ello, se precisa formalizar procedimientos que posibiliten alcanzar, en lapsos más bien reducidos, la definitividad de las decisiones de los tribunales de justicia y de sus respectivas fundamentaciones. Para ello, por ejemplo, se fijan plazos cuyo incumplimiento traerá aparejados la prescripción de las acciones procesales, el abandono de los procedimientos o la nulidad de las actuaciones.

Esta inconveniencia de dejar permanentemente abiertos los problemas prácticos incide, además, en el uso de expresiones realizativas en las sentencias definitivas -cuyo es el caso del "se encuentra probado"-, pues constituyen mecanismos que facilitan el cierre de las discusiones. ${ }^{9}$ En otras palabras, cuando un tribunal que opera dentro de su

${ }^{8}$ Nietzsche, F. Sobre verdad y mentira. Miluno, Buenos Aires, 2008, p. 25.

${ }^{9}$ No resulta de extrañar que una de las categorías claves de realizativos que propone J. L. Austin sea la de los judicativos (verdictives). Austin, J. L. Palabras y acciones. Cómo hacer cosas con palabras. 1ª ed. Paidós, Buenos Aires, 1971, pp. 200-203. 
esfera de competencia llega a decir que "algo está probado", provocará sobre un auditorio privilegiado el efecto de bloquear nuevas problematizaciones -al menos en el contexto de la adjudicación- y de conceder al hecho probado el estatus de soporte legitimado para la imposición de penas u otras consecuencias.

Alf Ross - con cierto desenfado y con no poca razón- ha planteado al respecto que " [...] en virtud de que un orden jurídico faculta a la persona o grupo de personas competentes para desencadenar, mediante palabras, las fuerzas que ponen en movimiento la maquinaria legal, la realización de un acto jurídico viene a ser semejante a la magia: las palabras crean el efecto que nombran". ${ }^{10}$ Ahora bien y sin perjuicio de que el acto lingüístico clave para que se entienda -en el contexto de un juicio- que alguien pueda ser tratado como si hubiera realizado determinada acción adopta la forma básica de: "está probado que...", los sistemas jurídicos suelen exigir para su validez que éste sea conectado con una historia introducida en la sentencia y que tiene como base soportante declaraciones de testigos, exhibición de objetos, etc. ${ }^{11}$

¿Será todo esto una manera astuta de eludir el problema de la exigencia prima facie de buscar la verdad lo mejor que se pueda? Creo que no, pues dentro del escenario de la adjudicación -y a pesar de la definitividad con la que el efecto de la cosa juzgada permite blindar cualquier decisión- las sentencias serán siempre susceptibles de crítica, si fuere el caso que aquéllas no se hubieren ajustado a reglas epistémicas útiles para aproximarnos a la verdad. La exigencia de medios y no de resultados que recae sobre los jueces evita un eventual bloqueo del proceso de adjudicación y, a la vez, dificulta su banalización. Esto, por cuanto, por una parte, se reconoce la imposibilidad de demostrar de manera infalible que la historia construida (y que da cuenta de la pasada interacción que habría habido entre acusado y víctima o demandante y demandado) haya efectivamente ocurrido; y por la otra, resulta suficientemente sensata como para legitimar una actividad crítica sobre el juez indolente, sesgado o corrupto que prescinde de la verdad como criterio ideal de validación de los discursos, cuya finalidad es la de dar cuenta de los hechos de un caso. Al reconocerse la imposibilidad de llegar a demostrarse en términos absolutos ¿cómo es o cómo ha sido el mundo?, la fuerza de la verdad como meta a alcanzar en el proceso de adjudicación no se diluye, sino que adquiere su justa dimensión, tal como ocurre en otras esferas de nuestras vidas.

Ahora bien, en cuanto a la interrogante acerca de cómo desenvolvernos en un terreno en el que se precisará, entonces, algo de verdad pero no toda, ${ }^{12}$ resulta útil tener presente

${ }^{10}$ Ross, Alf. Auge y Decadencia de las Expresiones Realizativas (1974), p. 187. Disponible en http://www. juridicas.unam.mx/publica/librev/rev/boletin/cont/21/est/est11.pdf.

${ }^{11}$ Cfr. Austin, J. L. Palabras y acciones. Cómo hacer cosas con palabras. $1^{\text {a }}$ ed. Paidós, Buenos Aires, 1971, pp. $55-56$.

${ }^{12}$ Una postura fuerte respecto de la irrenunciabilidad de la verdad como categoría que configura lo probado puede verse, en especial, en Taruffo, M. ¿Verdad negociada?, en Revista de Derecho de la Universidad Austral de Chile, Vol. XXI, N 1, julio de 2008, pp. 129-151. 
que en los sistemas jurídicos se estipulan reglas de segundo nivel en el contexto de la prueba. Así, no sólo hay reglas que protegen valores epistémicos, sino también reglas que protegen valores no epistémicos e incluso una categoría que, reconociendo los límites del conocimiento humano, posibilita operar válidamente en un contexto de incertidumbre, las que han sido llamadas por Larry Laudan: reglas que cautelan valores quasi epistémicos. ${ }^{13}$ Las reglas pertenecientes a esta última categoría no buscan directamente incrementar el nivel de verdad en las reconstrucciones fácticas como ocurriría con las primeras, ni tampoco evitar la vulneración de derechos fundamentales, como podría suceder con las segundas. A través de ellas, se pretende establecer cómo los tribunales que aspiran a hacer bien las cosas debieran distribuir entre las partes los errores epistémicos en que inevitablemente incurrirán. Dentro de esta categoría se sitúan los estándares de prueba.

Es importante hacer la aclaración de que se trataría de errores epistémicos, esto es, de equivocaciones que llevan a atribuir al acusado o demandado ciertas conductas que en realidad no ocurrieron; o bien, conductas que sí se produjeron en la realidad y fueron consideradas como inexistentes en las sentencias.

Los estándares de prueba permiten, entonces, operar válidamente en contextos de incertidumbre. Esto, por cuanto las decisiones que se lleguen a adoptar en el curso de la adjudicación y que pudieren eventualmente estar afectadas a errores epistémicos, de todas formas podrán ser calificadas como decisiones conforme a derecho; ello por la vía de definir cuánta información y análisis será requerido para superar las exigencias inherentes a la carga de la prueba que ha sido impuesta sobre una de las partes. Dicho de otra manera y en forma algo reiterativa, los estándares de prueba dan directrices acerca de cómo debiera distribuirse el potencial error en que podrían incurrir los jueces al dar por probada la historia favorable a las pretensiones del demandante o del acusador.

Los estándares de prueba constituyen, así, normas de segundo nivel que funcionan dando directrices a los jueces acerca de cómo debieran operar con normas de primer nivel o sustantivas, en un contexto en que sin ellas no habría parecido posible su aplicación plenamente justificada, en razón de los posibles errores en que podría incurrirse. Los estándares de prueba se hacen cargo de la falibilidad del conocimiento que será utilizado como uno de los pilares de la decisión judicial, indicando que para tratar a las personas atribuyéndoles, por ejemplo, el estatus de ladrón o de buen padre o buena madre, se requerirá alcanzar un cierto nivel de comprobación; la que, en todo caso, nunca será suficientemente fuerte como para despejar toda duda en cuanto a que lo que ha sido probado ha efectivamente ocurrido en la realidad. ${ }^{14}$

Como conclusión preliminar, entonces, puede sostenerse que los estándares de prueba autorizan la aplicación de una pena o reconocimiento de un beneficio, incluso

${ }^{13}$ Laudan, L. "Por qué un estándar de prueba subjetivo y ambiguo no es un estándar", en DOXA 28 (2005), pp. 96-97.

${ }^{14}$ Cfr. Laudan, L. Truth, error and Criminal Law. Cambridge University Press, Cambridge, UK, 2006, p. 66. 
habiendo riesgos de errar en el proceso de reconstrucción de la realidad. Para ello bastará (¡lo que no es poco!) que en los intentos de demostración y de falsación de las hipótesis en competencia, aquella historia compatible con la condena llegue a superar las exigencias previstas en el respectivo estándar de prueba.

\section{Distintos ESTÁNDARES DE PRUEBA PARA EL MUNDO CIVIL Y PARA EL MUNDO PENAL}

En su libro Tuercas y tornillos, Jon Elster sugiere que la racionalidad de una acción sería la resultante de que un agente haya operado de manera óptima en tres niveles distintos. El primero de ellos tiene que ver con que la acción elegida por el agente haya constituido el mejor medio para conseguir sus deseos y habida consideración de sus creencias; el segundo, correspondería a que dichas creencias se hayan formado de manera óptima a partir de las pruebas que estaban disponibles; y el tercero, se vincularía con que la cantidad de pruebas recabadas haya sido la adecuada, en vista de la relevancia asignada a la acción que se emprenderá y a sus costes esperados de producción. ${ }^{15}$ El enfoque de Elster resultará útil para comprender las razones que subyacen a la estipulación de uno u otro estándar de prueba, en ámbitos específicos de los sistemas jurídicos.

A pesar de que los estándares de prueba se asocian directamente al problema de la cantidad óptima de prueba que sería requerida para la adopción de una decisión racional, destinaré el siguiente párrafo a la tarea de situar en el contexto judicial los alcances de los dos primeros niveles mencionados por Elster. Ello no podrá sino ser a costa de una gran simplificación y de la petición a ustedes lectores que tengan en cuenta lo que ya ha sido dicho en la primera parte de este trabajo.

Si bien es cierto hay distintos deseos de los jueces que pueden competir a nivel de su subjetividad -en cuanto a qué es lo que se buscaría lograr cuando optan por condenar o por absolver al acusado, o bien si deciden acoger o rechazar las pretensiones del demandante (prestigio, venganza, piedad, etc.)-, a nivel sistémico es indudable que se trataría de un asunto que prima facie empecería sólo al legislador; ello habida cuenta del rol que a los tribunales se les asigna como aplicadores del derecho. ${ }^{16}$ Ahora bien, para efectos de poder llegar a satisfacer tales deseos impuestos desde afuera el medio óptimo será la aplicación de las soluciones que se encuentran estipuladas en las reglas generales de conducta que han sido promulgadas por la autoridad competente; ello, siempre

15 Elster, J. Tuercas y tornillos. Una introducción a los conceptos básicos de las ciencias sociales. Gedisa, Barcelona, 1996, 1989, pp. 31-39.

${ }^{16}$ Por cierto se trata de una afirmación que debiera ser matizada en razón de los problemas propios de la formulación de reglas en lenguajes naturales, de las incompletitudes e incoherencias que pueden aquejar a los sistemas jurídicos, de los cambios profundos en las sociedades que pudieren hacer aconsejable revisar la conveniencia de excluir todo balance de razones a partir de la excusa de que algo se encuentra ordenado por el legislador, etc. Sobre los distintos modelos de proceso véase Damaška, Mirjan. Las caras de la justicia y el poder del Estado. Análisis comparado del proceso legal, Editorial Jurídica de Chile, Santiago, 2000. 
y cuando hayan podido constatar la existencia de lo que Alf Ross ha llamado hechos operativos. ${ }^{17}$ Es decir, se espera la aplicación de las soluciones normativas cada vez que a partir de las creencias que han ido moldeándose conforme a las reglas procedimentales del sistema sea dable sostener que el acusado o demandado ha(n) incurrido en la(s) conducta(s) descrita(s) en la condición de aplicación de una norma con la que ésta(s) se pueda(n) hacer calzar. En cuanto al proceso de formación de tales creencias, los jueces deberán ceñirse a las reglas que fijan los límites acerca de qué es lo que podría servir de soporte a lo probado, como asimismo acerca de qué clase de inferencias sería legítimo realizar a partir de la información disponible. Es decir, los jueces deberán ceñirse a las reglas que siguiendo a Larry Laudan han sido calificadas -algunas líneas atrás- como protectoras de valores epistémicos y no epistémicos.

En cuanto a la optimización de las decisiones judiciales, es necesario enfatizar que para la racionalidad de la elección de un determinado curso de acción no siempre será necesario contar con el máximo de información potencial, incluso si ello pudiere significar la renuncia a la generación de datos de alta calidad epistémica o de mayor relevancia que aquéllos con los cuales ya se cuenta. El mismo Jon Elster -esta vez en Juicios salomónicos- ha indicado que: "La eficacia de la acción puede destruirse tanto por acumulación de pruebas escasas como por acumulación de pruebas excesivas. La cantidad óptima de pruebas está determinada en parte por nuestros deseos: las decisiones más importantes vuelven racional la acumulación de más pruebas”. ${ }^{18}$

Permítaseme un ejemplo sencillo para ilustrar lo anterior: Imaginemos que Lorenzo está en viaje de negocios en Florencia, disponiendo sólo de una tarde libre. Para optimizar su tiempo hace un listado de sitios y piezas artísticas que le gustaría conocer (define sus deseos), apareciendo en un lugar de privilegio las famosas Puertas del Paraíso de Ghiberti, los frescos de Masaccio y El Nacimiento de Venus de Botticelli. A pesar de que Lorenzo disfruta mucho con el arte se reconoce como un amateur: de hecho, ignora dónde se hallan específicamente las obras que pretende visitar y, en vista de ello, opta por preguntar a otros turistas y leer letreros en la vía pública que le pudieren ayudar a encontrarlas (define las fuentes de información relevantes para formar sus creencias y de ellas hace depender el curso de acción a tomar). Así, estando en la Piazza Michelangelo pregunta por la Puertas del Paraíso y dos mujeres hispanoparlantes que van leyendo una guía de la ciudad -y cuya edad Lorenzo estima entre 55 y 65 años- le señalan que las podrá apreciar en el Baptisterio de San Juan (a Lorenzo le basta con esa información, aun cuando podría recabar más). Al llegar a dicho lugar, una serie de letreros confirman que en uno de los costados del Baptisterio está la referida obra de Ghiberti (la creencia es fortalecida). Luego de maravillarse con la perfección de las placas observadas, Lorenzo continúa su paseo

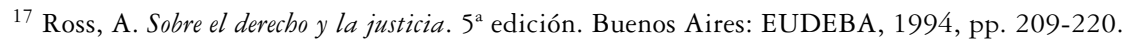

18 Elster, J. Juicios salomónicos. Las limitaciones de la racionalidad como principio de decisión. $1^{\text {a }}$ edición. Gedisa, Barcelona, 1991, p. 13. 
por la ciudad y guiado por lo que dicen otros turistas y los letreros entra al Museo de los Uffizi donde observa El Nacimiento de Venus y luego se dirige a la Capella Brancacci para gozar de los frescos de Masaccio. Ya en el avión de regreso a su país, se le nota radiante en razón de haber llegado a conocer obras trascendentales de Ghiberti, Masaccio y Botticelli.

Pensemos ahora en Simonetta, una reconocida experta en tasaciones y conservación de obras de arte, quien ha sido contratada por una compañía aseguradora para que evalúe las condiciones de una póliza que se está negociando para cubrir los riesgos del traslado de las Puertas del Paraíso a una exposición que se montará en el Metropolitan Museum of Art de Nueva York. Simonetta, en la ejecución de su trabajo, deberá analizar el estado de conservación de las placas de Ghiberti y sugerir medidas para evitar la producción de cualquier daño a éstas (desea que sus recomendaciones sean las más adecuadas). Para tales efectos, decide viajar a Florencia y así analizar in situ el estado en que se encuentran las Puertas del Paraíso (define los medios para efectos de elegir un curso de acción). A diferencia de Lorenzo, nuestra experta revisa en la biblioteca pública algunos libros especializados y navega en Internet en sitios que califica como serios para informarse dónde se hallan exactamente los originales de Ghiberti. El primer libro que es revisado señala que las Puertas del Paraíso se encuentran en el Baptisterio de San Juan, observando ella que el año de edición de éste era 1920. Pensando que la obra pudo haber sido trasladada con posterioridad sigue explorando nuevas fuentes (suspendiendo provisionalmente la creencia inicial de que las placas originales estarían situadas en el Baptisterio de San Juan). Al perseverar en su búsqueda de nueva información, Simonetta llega a la conclusión de que las placas que se exhiben en el Baptisterio son réplicas de las originales, las que en realidad estarían situadas en unas cámaras que se hallan en un costado del Museo dell'Opera del Duomo, adonde fueron trasladadas en la década del 60.

Según habrá sido advertido, Simonetta alcanzó la meta que se había propuesto (analizar los originales), en cambio, Lorenzo, no (al menos, respecto de la obra de Ghiberti). ¿Podría decirse, entonces, que Simonetta actuó racional o correctamente y Lorenzo, en cambio, lo hizo de manera inadecuada o irracional? Indudablemente, no. Para Simonetta el coste del error era demasiado alto y, por tanto, era racional que se premuniera de bastante información para efectos de acometer la interrogante ¿dónde están ubicados actualmente los originales de Las Puertas del Paraíso? Para Lorenzo, el costo del error no era tan alto (se jugaba fundamentalmente un placer estético, el que de todas formas alcanzó -al menos en una importante medida- al contemplar las réplicas) y en vista de ello apreció como suficiente la información de regular calidad; la que, en todo caso, sí le permitió conocer los originales de los frescos de Masaccio y El Nacimiento de Venus. Para Lorenzo el costo alternativo del tiempo era demasiado elevado en comparación con el beneficio que representaba la precisión del conocimiento, tanto es así que en el caso que hubiera hecho una investigación exhaustiva que le hubiera llevado a la misma conclusión de Simonetta, probablemente habría llegado al Museo dell'Opera del Duomo cuando éste ya se encontrare cerrado para los visitantes. 
El caso de Lorenzo y Simonetta refleja, de buena manera, las vicisitudes por las que puede pasar el legislador al momento de definir los distintos estándares de prueba que regirán en el sistema jurídico. Según el daño que puede llegar a provocar un error que afecte a la manera de reconstruir los hechos, se exigirá una mayor o menor exhaustividad para la producción y análisis de la información útil para servir de soporte de historias.

Un buen estándar de prueba debiera tener en consideración los bienes que se encuentran en juego, la importancia que puede llegar a tener la rapidez o lentitud en la toma de la decisión y los costos esperados de la producción y análisis de la información potencialmente relevante. En vista de ello, los sistemas jurídicos suelen considerar, al menos, dos estándares de prueba para efectos de enfrentar la incertidumbre que es propia, tanto en los casos penales como en los casos civiles. En los casos penales -como se sabe- lo que está en juego es la aplicación de un castigo sobre una persona, de la cual se sospecha que ha cometido cierta conducta que el sistema jurídico intentó infructuosamente desalentar mediante la estipulación de un tipo penal. Por cierto, los riesgos más evidentes asociados a la disposición de información subóptima serán, por una parte, la aplicación de una pena sobre quien no la merecía (en razón de no haber realizado la acción o no haber incurrido en la omisión que se le atribuye) y, por la otra, la falta de castigo sobre quien sí lo merecía (esto es, sobre quien efectivamente cometió la conducta por la cual había sido acusado). Considerando la relevancia que puede llegar a tener la disponibilidad de buena información y de un adecuado análisis de ésta para la disminución del potencial error, el estándar de prueba penal suele estipular que si, al momento de dirimir, el juzgador permaneciere con dudas respecto de la culpabilidad del acusado, debiera optar por la absolución de éste. En el ámbito penal se podría entender, entonces, que habría una asimetría en el impacto del error, desde el punto de vista valorativo.

Ya desde antiguo se ha entendido que el espacio de incertidumbre propio de la reconstrucción de los hechos que sirven como insumo clave para la toma de decisión, debe ser gestionado en los casos penales teniendo especial cuidado que no se llegue a sancionar a un inocente, aun cuando con ello se incremente el riesgo de errar por vía de absolver a los culpables. ${ }^{19}$

Así, a modo de ejemplo, en Las Siete Partidas encontramos una defensa para la aplicación de un estándar de prueba en asuntos penales que cuida, especialmente, de no imponer un castigo sobre el inocente. Se dice en ellas que “... los judgadores todavia deuen eftar mas inclinados e aparejados para quitar los omes de pena, que para condenar los, en los pleytos, que claramente non pueden ser provados o que fueren dudofos; ca mas fanta cofa, e mas derecha de quitar al ome de la pena que

${ }^{19}$ Esto no siempre ha sido valorado de esta manera. Así, por ejemplo, en el libro de los Proverbios se observa un repudio uniforme hacia el error, indiferentemente sobre quien éste recaiga: "Justificar al malo y condenar al justo: ambas cosas abomina Yaveh (17:15). 
merecieffe, por yerro que ouieffe fecho, que dar la al que la non merescieffe, nin ouiffe fecho alguna cofa por qué". ${ }^{20}$

Por su parte, el matemático Laplace planteó en la época de la Ilustración que: "Indudablemente, para condenar a un acusado, los jueces necesitan las pruebas más seguras de su delito. Pero una prueba moral siempre es sólo una probabilidad, y la experiencia ha mostrado demasiado los errores de que son susceptibles los juicios criminales, aun aquellos que parecen los más justos. La (imposibilidad) de reparar estos errores es la razón más fuerte de los filósofos que han querido proscribir la pena de muerte. Tendríamos, pues, que abstenernos de juzgar si hubiera que esperar la evidencia matemática. Pero el juicio se impone por el peligro que resultaría de la impunidad del crimen". 21

En el ámbito civil los bienes en juego -y con ello los riesgos asociados al error-son diferentes a los que se producen en el espacio penal. Aun cuando los resultados deseados pueden ser formulados en términos lógicamente equivalentes a la forma en que se haría en casos penales, ${ }^{22}$ el impacto del error potencial se valora de manera distinta. En el error civil lo que generalmente se está provocando es la realización de actos que distribuyen bienes (dinero, empleos, tuiciones, etc.), bajo la aparente justificación de que así se estaría haciendo circular dichos bienes conforme a lo previsto por el sistema jurídico; o al contrario, se estaría bloqueando una cierta forma de distribuir bienes bajo la aparente justificación de que ella no sería conforme a lo previsto por el sistema jurídico. En el mundo del proceso civil habría una simetría o indiferencia en el impacto del error, esto es, tanto beneficiar al demandante a costa del demandado como beneficiar al demandado a costa del demandante, sería igualmente desaconsejable.

Otra de las razones para considerar un estándar de prueba bastante exigente para el mundo penal y no tanto para el mundo civil se vincula con otra situación de asimetría, esta vez, en cuanto a los recursos disponibles para estructurar la defensa de los intereses de las partes involucradas en un juicio. Por regla general, la diferencia entre los recursos económicos y técnicos usualmente destinados por las partes de un juicio penal, para efectos de generar información relevante, es muy notoria. El órgano encargado de la persecución

${ }^{20}$ Partida VII. Título XXXI, ley IX.

${ }^{21}$ Laplace, P. S. Ensayo filosófico sobre las probabilidades. Espasa-Calpe, Buenos Aires, 1947, p. 145. (Nota: en la traducción por la que se cita dice erróneamente posibilidad donde ha sido escrito imposibilidad, en este mismo sentido ver cita en inglés en Eggleston, R. "Sixth Wilfred Fullagar memorial lecture «beyond reasonable doubt»”, en Monash University Law Review, vol. 4, december 1977, p. 1. En el ámbito del Common Law se producía un desarrollo similar, en este sentido a mediados del siglo XVIII, en un pasaje muchas veces citado del volumen IV de su Commentaries on the Laws of England, William Blackstone señalaba que "Es mejor que diez culpables escapen, antes que un inocente sufra". Disponible en http://www.lettere. unipd.it/pre/static/docenti/77/JS + MILL-CapitalPunishment.pdf.

${ }^{22}$ Así, por ejemplo, para expresar los deseos en cuanto al curso de acción que debiera ser elegido podría decirse: Se acogerá la pretensión (acusación) si el demandado (acusado) efectivamente bubiere realizado la conducta a la que se asocia la existencia de una obligación (la aplicación de una pena) y se rechazará lo pretendido si el demandado (acusado) no bubiere efectivamente realizado la conducta que genera la obligación (la pena). 
de los sospechosos de haber cometido un crimen cuenta casi siempre con un decidido apoyo de la Policía y de laboratorios especializados, en la búsqueda de ejecutar correctamente su cometido. A contrario, los recursos con que cuenta el acusado para defenderse ante la imputación que sobre él recae, suelen ser más bien precarios. En el ámbito civil, en cambio, no hay diferencias iniciales que siempre favorezcan a los demandantes por sobre los demandados, ni viceversa. No tener esto en consideración, llevaría a que si se instaurase en materia penal un estándar de prueba que predicase la indiferencia respecto de sobre quién debiera recaer el riesgo de error, el número de equivocaciones de condena a inocentes seguramente excedería al de absoluciones a culpables. ${ }^{23}$

Estas desigualdades, probablemente, han sido las determinantes para que sólo en el ámbito civil opere un estándar de prueba relativamente débil para efectos de que el demandado llegue a ser condenado. ${ }^{24}$

La diferencia advertida entre ambos estándares de prueba debiera ser suficiente como para llegar a provocar fuertes implicaciones prácticas. Una de las situaciones en la que las diferencias se revelaron de manera especialmente nítidas ocurrió en un bullado caso que protagonizó Orenthal James (O.J.) Simpson. Como se sabe, quien años antes había sido aclamado como un excepcional jugador de fútbol americano, fue acusado de haber dado muerte a su ex cónyuge Nicole Brown y a su amigo Ronald Goldman, en junio de 1994. El jurado lo absolvió en el proceso criminal seguido en su contra el año 1995, bloqueándose, así, la aplicación de una elevada pena en su contra. Sin embargo, en 1997 , en una causa civil un nuevo jurado lo halla culpable del mismo hecho condenándosele esta vez a pagar una indemnización de varios millones de dólares.

Más allá de las razones que pudieren invocarse en cuanto a la forma en que se llevó a cabo la investigación o se conformaron los jurados, la discrepancia entre ambas decisiones no implica necesariamente -al menos desde la perspectiva estrictamente procedimental- que una de las decisiones haya sido correcta y la otra, incorrecta; ello por cuanto en el ámbito criminal operaba un estándar de prueba exigente que no logró ser superado, el cual, en cambio, en el proceso civil sí alcanzó a ser satisfecho.

${ }^{23}$ Cfr. Posner, R. "An Economic Approach to the Law of Evidence”, en 51 Stanford Law Review (19981999), p. $1505,1543$.

${ }^{24}$ Más aún, a diferencia de lo que ocurre en el ámbito penal, la depuración del estándar de prueba civil suele suscitar un nivel de atención bastante reducido y, al menos en el caso chileno, ni siquiera se encuentra definido por el legislador. En países donde la discusión relativa a los estándares de prueba es intensa, como ocurre en los del sistema del common law, la definición precisa acerca del estándar de prueba civil no parece estar del todo consolidada. Así, Richard Eggleston sostiene que "Es un hecho singular que luego de siglos de determinación de lo que está probado, por parte de jueces y jurados, bajo la dirección del estándar de prueba, hay todavía mucha incertidumbre acerca del que es requerido en el ámbito civil. Eggleston, R. "Evidence, proof and probability”. $2^{a}$ ed... Butterworths, London, Edinburgh, Dublin, 1997, p. 129. 
Al observarse la manera en que se encuentran formulados, es fácil consensuar que los estándares de prueba fijan -en términos muy abstractos ${ }^{25}$ - la cantidad de información mínima que sería necesario allegar al juicio con miras a poder justificar una sentencia favorable al demandante o acusador; ${ }^{26}$ la calidad de las inferencias que a partir de ellas debieran ser construidas, y la manera en que será distribuido el posible error en que pudiere incurrirse al adoptar la decisión de condenar o absolver al acusado, o bien de acoger o rechazar la demanda. Así, por ejemplo, la información deberá ser bastante completa, la argumentación especialmente sofisticada y el riesgo de error de condena a un inocente bastante reducido, para el caso de que se llegue a entender que el estándar de prueba penal ha llegado a ser satisfecho por la parte acusadora en un asunto concreto. No ocurrirá lo mismo si el estándar de prueba respectivo no impusiere requisitos elevados para la parte sobre la cual recae la carga de la prueba, como es la situación que como se ha dicho ocurre en los casos civiles. ${ }^{27}$

Lo anterior significaría, más o menos, lo siguiente: en los casos penales se requiere de abundante información para llegar a tomar una decisión de condena sobre el acusado, aun cuando éste no se defendiere, pues independientemente que ello ocurra las lagunas de información que pudieren perdurar al concluir el proceso podrían hacer aparecer como plausibles una o más versiones alternativas que sean compatibles con la inocencia del demandado. Por cierto, si la defensa -como de ella en términos generales se espera- asume un rol activo en la fase de producción de información que rivalice con la que ha sido presentada por el acusador, la fuerza de la prueba incriminatoria tendrá que resultar suficientemente potente como para tornar escasamente plausibles las historias de la defensa que son soportadas con aquella prueba de descargo que fue producida en el curso de la audiencia de prueba respectiva.

El estándar de prueba civil, en cambio, podría llegar a satisfacerse aun cuando no se produjere mucha información. Más precisamente, es suficiente quebrar la inercia propia de la constatación de que cada persona, por regla general, celebra contratos o bien produce daños civiles que la vinculan sólo con un porcentaje muy reducido de la población. Para dar por probada una historia en el ámbito civil no se requiere, entonces, que todas las alternativas que pudieren rivalizar con ella sean calificadas como poco plausibles: basta con que la historia del demandante sea un poco más fuerte que las reconstrucciones fácticas que se muestren como incompatibles con sus pretensiones. Así, si la parte demandada no se defendiere, bastará con que la historia de la demandante venza a la aludida inercia que se asocia al hecho que las personas tenemos vínculos jurídicos limitados. Si, en cambio, se presentaren versiones específicas de defensa por parte del

${ }^{25}$ Esto, por ejemplo, ha llevado a la producción de una abundante literatura en países anglosajones, en la que se busca precisar qué podríamos llegar a entender que significa beyond a reasonable doubt.

${ }^{26}$ En razón de la estructura de la carga de la prueba -y como regla de clausura-, si no se supera el estándar de prueba estipulado, los jueces deben absolver al acusado o rechazar la demanda.

27 En el mundo anglosajón también operaría para algunos asuntos civiles un estándar más exigente que el que ya ha sido señalado, esto es, clear and convincingly. Éste de todas formas sería más bajo que el exigible para casos penales. 
demandado - ya sea intentando demostrar la falsedad de la historia del demandante o bien presentando una reconstrucción alternativa de lo que habría ocurrido-, se requerirá que la historia del demandante sea más potente que las formuladas por la demandada, aun cuando estas últimas sean, de todas formas, plausibles.

En la práctica, los estándares de prueba son interpretados con muchos matices, según sea la carga o beneficio a distribuir en el caso concreto. ${ }^{28}$ Por cierto, esta forma de entenderlos no pareciera resultar del todo fiel a la manera abstracta en la que éstos se encuentran formulados, y en que no se da cabida para el establecimiento de tales diferencias. Así, por ejemplo, en el ámbito penal puede advertirse que en situaciones en que la pena que se podría aplicar resultaría muy elevada, la duda razonable como límite a la aceptación de historias que persiguen la condena del acusado suele adquirir una relevancia mayor que en los casos en que los castigos resultarían más bien bajos. ${ }^{29}$ En los juicios civiles pueden advertirse, también, ciertas diferencias en la manera que el estándar de prueba es interpretado según los bienes que se encuentran en juego. ${ }^{30}$ Sin embargo, lo que probablemente llama más la atención respecto a lo último es que los tribunales operan de becho con un estándar de prueba que, por regla general, es más elevado que el que potencialmente se podría hacer derivar de expresiones tales como preponderancia de la prueba o balance de las probabilidades. De esta manera, el riesgo que recae sobre el demandante de obtener erróneamente sentencias adversas resulta más elevado que el riesgo de error que soporta el demandado. ${ }^{31}$ Más allá de la difícil justificación que pudiera intentar construirse para establecer diferencias en situaciones en las que el legislador no haya dado señales

${ }^{28}$ Entre los anglosajones son conocidas las palabras de Lord Denning pronunciadas en el caso Bater v/s Bater, según las cuales éste reconoce que a pesar de que se esté operando con un mismo estándar de prueba, los tribunales exigirán diferentes grados de probabilidad para considerar probados los hechos, ello dependiendo del problema de que se trate. Ver, entre otros, en Anderson, T.; Twining, W. Analysis of evidence. How to do things with facts. Weidenfeld and Nicolson, London, 1991, p. 364.

${ }^{29}$ Ver estudio de Simon, R.; Mahan, L. "Quantifying burdens of proof. A view from the bench, the jury and the classroom”, en Law and Society Review, February 1971, p. 319-330, especialmente lo indicado en la tabla 10, que refiere a la probabilidad que se estima debiera ser alcanzada para condenar a los acusados por distintas clases de delitos.

${ }^{30}$ Para cierta clase de asuntos algunos sistemas jurídicos establecen un estándar diferente y más exigente en las causas civiles. Dicho estándar se conoce bajo la fórmula de "clara y convincentemente".

${ }^{31}$ En esta línea de pensamiento, es interesante el análisis que Frederick Schauer lleva a cabo a partir del famoso caso Smith v/s Rapid Transit. En éste, los tribunales rechazaron la demanda de indemnización de perjuicios, pese a que se habría allegado prueba suficiente como para demostrar que un accidente sufrido por Betty Smith en el año 1941 fue provocado por un bus que ella no alcanzó a identificar directamente; como asimismo, que la empresa demandada estaba a cargo de manera exclusiva del recorrido que pasaba por el lugar del accidente. Lo relevante para el rechazo de lo solicitado fue que habría habido historias alternativas plausibles no desechadas, como sería el caso de que hubiere sido un bus fuera de recorrido de otro propietario. Schauer reclama que ello pudiere haber sido razonable si se hubiese aplicado un estándar como el del más allá de toda duda razonable, pero no en el caso que se aplicare un estándar civil, según el cual bastaría demostrar que la historia del demandante era mejor que la del demandado. Schauer, F. Profiles, probabilities and stereotypes. The Belknap Press of Harvard University Press, Cambridge \& London, 2003, pp. 79-107. 
que así puedan operarse, tales prácticas pueden ser entendidas como señales de alerta ante estándares de prueba que no son aptos para hacerse cargo razonablemente de la manera en que los potenciales errores debiesen ser gestionados.

\section{IV. ¿POR QUÉ UN ESTÁNDAR ESPECIAL PARA LOS CASOS DE VIOLACIONES A LOS DERECHOS HUMANOS?}

Si se prescindiese de las complejidades políticas y sociales que acompañan, con frecuencia, a la realización de los juicios por violaciones a los derechos humanos, éstos parecieran no diferir mayormente de casos penales y civiles ordinarios en los cuales rara vez se problematiza la aplicación de estándares de prueba, tales como el del "más allá de toda duda razonable" o de la "preponderancia de la prueba".

Así, con cierta frecuencia, llegan a los tribunales de justicia casos que a pesar de tener que ver, por ejemplo, con homicidios brutales, secuestros, lesiones provocadas a raíz de prácticas de tortura, etc., no dudaríamos en que para llegar a condenar al acusado a sufrir una cierta pena, el estándar de prueba que debiera superarse es el del "más allá de toda duda razonable". En el mismo sentido, puede decirse que los jueces, cuando deben resolver una petición de indemnización de perjuicios en contra, por ejemplo, de una empresa que a sabiendas usó pesticidas tóxicos que provocaron graves daños a la salud de sus trabajadores, tampoco debieran dudar en exigir la superación de un estándar de prueba civil, a pesar de la similitud que pudiese haber con asuntos constitutivos de violaciones a los derechos humanos.

Las razones por las cuales valdría la pena plantearse la exigibilidad de un estándar de prueba diferente a los restantes casos que ingresan a los tribunales de justicia nacen del hecho de que en los juicios por violaciones a los derechos humanos la verdad representa un criterio de evaluación de la corrección de las sentencias que tiene implicaciones algo diferentes a las usuales. Paso a explicarme.

Según ha sido dicho, los jueces requieren dar por probada cierta historia jurídicamente relevante, por cuanto ello provoca un efecto práctico clave en el proceso de adjudicación, esto es, sólo así pasarán a estar en condiciones de atribuir una consecuencia agradable (premio) o desagradable (castigo) a una o más personas involucradas en un proceso. Ello lleva a que se precise construir una historia suficientemente buena, habida cuenta de lo que está en juego y de los medios de los que se disponga para escudriñar el pasado. Sin embargo, una buena historia además de constituir una condición clave para la legitimación del castigo o del premio que ha sido impuesto por parte de los tribunales de justicia, cumple algunas funciones - si se quiere indirectas- tales como la disminución del efecto desmoralizador que se produce cuando se recibe una sentencia adversa, ${ }^{32}$ lo que tiene

${ }^{32}$ Ver Tyler, T. Why people obey the Law. Yale University Press, New Haven - London, 1990, pp. 5 y sgtes. 
bastante importancia para efectos de que no se llegue a creer por parte de las personas que resultaría indiferente ajustar la conducta a lo estipulado por el sistema jurídico, como también para estimular el cumplimiento espontáneo de lo que ha sido fallado. Eso no es todo, pues otro efecto ligado a la construcción judicial de historias -y que será el que aquí realmente interesará- tiene que ver con que aquéllas sirven para la solución de enigmas o, dicho en otras palabras, atribuyen un significado a trozos de la realidad que, en ocasiones, nos parecería insoportable que vagara en la obscuridad. ${ }^{33}$

Por cierto, lo último que ha sido mencionado no atañe sólo a los tribunales de justicia y bien podría involucrar a periodistas, historiadores u otras personas que estando interesadas contaren con las competencias básicas como para que sus historias sean tomadas en cuenta por auditorios que merecen que se les dé una respuesta plausible a sus enigmas. Sin embargo, la puesta en escena propia de un juicio en el que se enfrentan partes motivadas por influir en el órgano decisor con miras a la obtención de una sentencia favorable a sus intereses, constituye una oportunidad privilegiada para la producción de una historia que pueda llegar a ser reconocida como una buena reconstrucción de la realidad. Dicha meta implica que el conocimiento que se llegue finalmente a construir no se agote en la sola aceptación de creencias a nivel de nuestra pura subjetividad, incluso si el procedimiento que hubiésemos seguido para tales fines se presentase como suficientemente sensato. Más bien, lo que requerimos es que las creencias que estamos dispuestos a sostener lleguen a ser compartidas por un universo más o menos amplio de individuos o, dicho de otra forma, requerimos de un conocimiento intersubjetivo o de un conocimiento que genere consensos en determinados auditorios. ${ }^{34}$

Los requerimientos de intersubjetividad recién mencionados implican que los procesos de producción de textos judiciales que aluden a los hechos probados se estandaricen, es decir, los mecanismos tendientes a la creación de una historia que sirve para dar cuenta de lo que habría ocurrido deben cautelar de no exacerbar el rol a desempeñar por la pura subjetividad del juez, incluso si éste fuere reconocido como sabio y justo. ${ }^{35}$ Lo expresado, entonces, lleva a que en el instante que se le otorga competencia a los jueces para dirimir qué es lo que ha sido probado y qué es lo que no ha alcanzado dicho estatus, se ponga en movimiento aquello que se conoce como la distribución social del conocimiento.

33 Así, por ejemplo, Larry Laudan ha señalado que el principal costo de una errada absolución es que "una persona culpable de un crimen permanece libre, sin castigo y tal vez cometerá otros crímenes; la justicia no es otorgada; la víctima del crimen no cierra el episodio y se aleja amargada de la experiencia porque la justicia no fue hecha". Laudan, L. Truth, error and Criminal Law. Cambridge University Press, Cambridge UK, 2006, p. 69.

${ }^{34}$ Hay, sin embargo, situaciones como las propias de los juicios con jurados en lo que importa más la sinceridad del agente que la intersubjetividad amplia del conocimiento generado. Lo mismo podría entenderse en el caso de la aplicación de estándares de prueba que pudieren ser calificados como subjetivos. Respecto de esto último pueden verse las críticas de Larry Laudan acerca de cierta manera de entender el más allá de toda duda razonable, que es característico en los juicios penales. Laudan, L. "Por qué un estándar de prueba subjetivo y ambiguo no es un estándar”, en DOXA 28 (2005), pp. 95-113.

35 Esta constatación probablemente es la responsable de las fuertes críticas que desde hace un tiempo ha recibido el modelo de la Intime conviction popularizado fundamentalmente a partir de la Revolución Francesa. 
Cuando se habla de distribución social del conocimiento ${ }^{36}$ se está apuntando, como se sabe, a la necesidad de que haya un cierto nivel de especialización en determinados saberes, de manera tal que no se precise que todos tengamos que saber todo acerca de todo, sino que podamos contar con que ciertos temas específicos serán entregados, de manera primordial, a ciertos individuos especialmente calificados. ${ }^{37}$ Así, los jueces, en el caso de discrepancias en las historias presentadas por las partes bajo la pretensión de que se las considere como un fragmento de la realidad, cuentan con un reconocimiento a veces reforzado -por el uso de estrados, togas y martillos- de que lo que ellos declaren como probado, luego de haber respetado ciertos procedimientos, debiera ser suficiente como para provocar ciertas reacciones prima facie de parte de la ciudadanía en cuanto a que lo que ellos dicen merece ser tomado como si fuere cierto. ${ }^{38}$

Como consecuencia de la distribución social del conocimiento, la fuerza de los actos lingüísticos emanados de los jueces al momento de dar por probada (o no) cierta versión de los hechos, es diferente a la que podría esperarse prima facie de lo que pudiere ser dicho por cualquier ciudadano a quien no se le reconoce esta función de fijar la historia. ${ }^{39} \mathrm{Al}$ declarar un tribunal que se encuentra probado, por ejemplo, que Rodion mató a Aliona, esta declaración adquirirá un estatus privilegiado para efectos de fijar lo que será entendido como un fragmento de lo que constituye la bistoria de nuestra sociedad. Así, en las conversaciones, en los textos escolares, en los libros historia, o en el cine podrá decirse, sin necesidad de tener que llegar a justificarlo, que fue Rodion quien mató a Aliona, por la sola circunstancia de que un tribunal que actuó dentro de la esfera de su competencia haya declarado que Rodion mató a Aliona. Por cierto, el hecho de que Rodion haya matado efectivamente a Aliona podrá seguir siendo problematizado en la medida que las personas sigamos estando interesadas en ello; sin embargo, quien pretenda convencernos de que ello no ocurrió tendrá que hacerse

${ }^{36}$ Cfr. Berger, P; Luckman, Th. La construcción social de la realidad. 26a reimpresión. Amorrortu, Buenos Aires - Madrid, 2006, p. 63.

37 Es posible que las siguientes palabras de Hans Kelsen -las que aparentemente niegan toda relevancia a la verdad como criterio de validación de los enunciados fácticos de un juicio- cobren sentido si se les entienden como un reconocimiento de los jueces como individuos a quienes se les reserva socialmente la construcción del conocimiento en el contexto del ejercicio de la función de adjudicación: "La determinación del hecho condicionante, por parte del tribunal, es [...] constitutiva en todo sentido [...] No es el hecho en sí, el haber muerto un hombre a otro, sino el hecho de que un órgano competente según el orden jurídico haya establecido, conforme a un procedimiento determinado por ese orden, que un hombre ha cometido un homicidio, lo que configura la condición estatuida por el orden jurídico...". Kelsen, H. Teoría pura del derecho. $9^{a}$ ed. Porrúa, México D. F., 1997, p. 249. No obstante ello, creo que Kelsen no da cuenta con ellas de las peculiaridades del proceso probatorio que difícilmente puede ser entendido sin referencia a la pretensión de describir la realidad.

${ }^{38}$ Cfr. Cohen, L. J. "Belief and acceptance", en Mind, vol. XCVIII, 1989, pp. 367-389.

${ }^{39}$ Por cierto, un historiador o periodista reconocido como imparcial, estudioso y agudo podrá indudablemente provocar un impacto mayor que un tribunal que no cuente con una suficiente legitimación social, en cuanto a la formación de creencias en cuanto a qué ha realmente sucedido. Sin embargo, en condiciones de igualdad de condiciones de imparcialidad, estudio y agudeza, los jueces debieran encontrarse en una posición preferente para la construcción de historias compartidas por la gente acerca de cómo han sucedido las cosas. Asimismo, el número de casos que pueden llegar a ser abordados por periodistas o historiadores generalmente será bastante más reducido que los que podrían gestionar los tribunales. 
cargo de la inercia argumentativa que beneficiará a las representaciones compatibles con aquello que en su oportunidad fue fallado por el tribunal.

Hay ejemplos paradigmáticos en que no se da el efecto señalado, como sería el famoso caso Sacco y Vanzetti. La decisión del jurado de haber considerado a estos dos inmigrantes italianos como autores de un robo con homicidio en South Braintree el año 1920 no ha sido reconocida de facto como valiosa para el modelamiento de creencias de la gente, en cuanto a que ellos fueron efectivamente los autores de dicho crimen. Las razones para ello, sin embargo, no tendrían que ver con una ineptitud inherente de los fallos judiciales para construir prima facie ciertos trozos relevantes de la historia humana, sino con el hecho de que en dicho juicio fueron vulneradas reglas básicas para que el acto lingüístico de haber dado por probado ciertos hechos constituyese una forma legítima de ejercicio de la facultad de crear conocimiento. A ello, además, se suma una razón adicional como para no tomarse tan en serio la decisión de culpabilidad pronunciada por el jurado como mecanismo de reconstrucción de la realidad, el cual tiene que ver con que esta clase de órganos previstos en algunas formas de procedimientos no requiere justificar sus decisiones de dar o no dar por probados ciertos hechos, a contrario de lo que sí ocurre con los jueces.

El desplazamiento a un segundo plano de la función que, indirectamente, pudiere asociarse a las sentencias judiciales en cuanto a mecanismos útiles para la reconstrucción de la historia, parece en principio perfectamente razonable. Las vistosas implicaciones prácticas suelen agotar los espacios de relevancia y serán muy pocos los casos que estarán llamados a perdurar en el tiempo, en lo que es usual llamar nuestra memoria colectiva. Así, la labor de los jueces no parece tener sentido, sino en la medida que la decisión a su cargo potencialmente pudiera llegar a desembocar, por ejemplo, en la aplicación de una pena, en el reconocimiento de un vínculo de parentesco o, quizás, en la reincorporación a un puesto de trabajo. De hecho, se entiende, por ejemplo, que cuando la responsabilidad penal se extingue, los jueces deben dar un paso al lado y abandonar el conocimiento de un asunto que resultaba hasta ese momento de alto impacto para la víctima, sus familiares e incluso para los medios de comunicación. Sin perjuicio de ello, hay casos excepcionales en que aquello no ocurre: uno de estos casos se advierte en el artículo 474 del Código Procesal Penal chileno al posibilitar la puesta en movimiento del sistema judicial para corregir errores que hubieren afectado a personas ya fallecidas, lo que provocará efectos prácticos sólo indirectos.

Artículo 474 "La revisión de la sentencia firme podrá ser pedida, en cualquier tiempo, por el ministerio público, por el condenado o por el cónyuge, ascendientes, descendientes o hermanos de éste. Asimismo, podrá interponer tal solicitud quien hubiere cumplido su condena o sus herederos, cuando el condenado hubiere muerto y se tratare de rehabilitar su memoria”. 40

\footnotetext{
${ }^{40}$ En un sentido similar, puede verse el artículo 955 de ley de enjuiciamiento criminal española.
} 
En los juicios por violaciones a los derechos humanos el papel de los jueces en cuanto individuos socialmente competentes como para llegar a producir una determinada forma de conocimiento, a la cual se le atribuye la fuerza suficiente como para influir en lo que serán nuestras representaciones históricas, se presenta como mucho más relevante que en los demás casos que llegan a los tribunales de justicia. Esto, por cierto, tiene que ver con el impacto que provocan las violaciones a los derechos humanos en el seno de una comunidad medianamente madura, lo que traerá consigo que éstas constituyan un tema difícil de cerrar o sencillamente de asumir, mientras los enigmas que emergen respecto al ¿qué entenderemos que fue lo que realmente sucedió? no sean adecuadamente clarificados. ${ }^{41}$ La demanda de verdad, entonces, puede en ocasiones llegar a adquirir incluso mayor relevancia que las implicaciones prácticas directas, como lo serían las penas e indemnizaciones perseguidas en estos juicios.

En los juicios por violaciones a los derechos humanos es donde adquieren especial relevancia asuntos tales como el reconocimiento de errores por parte de instituciones que habrían estado involucradas en la producción de los delitos, los pronunciamientos de comisiones de verdad y reconciliación de naturaleza extrajudicial, etc., los que en otros juicios pudieren ser asuntos carentes de todo interés.

Lo señalado pudiere implicar que los estándares de prueba disponibles para el mundo penal y civil no sean especialmente aconsejables para dar cuenta de las peculiaridades de las violaciones a los derechos humanos. Esto constituye una razón suficiente para arriesgarse a formular una propuesta de estándar de prueba específico para este tipo de casos. Mi propuesta será que se exija un estándar de prueba que llamaré de la preferencia de las buenas explicaciones no derrotadas. ${ }^{42}$

En los juicios por violaciones a los derechos humanos se advierte una alta presión sobre los tribunales de justicia en orden a disponer de sentencias definitivas en las cuales se incluyan historias completas y bien fundadas acerca de los dramáticos episodios que han sido denunciados. Esto, por cierto, podría entenderse como que en este tipo de casos existe sobre los jueces una especial demanda de alcanzar la verdad como soporte para la toma de decisiones. Alcanzar la verdad en este contexto supone en realidad construir buenas explicaciones en las sentencias, ello en términos que puedan ser entendidas como una fiel reconstrucción de sucesos acontecidos con anterioridad. Lo expresado apuntaría -creo entender- no tanto al logro de un consenso en las creencias de un universo de hablantes relativamente amplio que pudiere independizarse de lo que efectivamente habría ocurrido, sino más bien a una forma de representación fiel de acontecimientos

${ }^{41}$ Sobre la función de la construcción de una memoria en el espacio público, ver Ricoeur, P. La memoria, la historia, el olvido. $2^{a}$ ed. Fondo de Cultura Económica, Buenos Aires, 2008, especialmente, pp. 412-434; 577-581.

${ }^{42}$ Pienso que el estándar propuesto cuenta con la virtud de no depender de la subjetividad del juez, como sí ocurre al menos en ciertas lecturas que pueden hacerse del más allá de toda duda razonable. 
efectivamente sucedidos, independientemente de lo que sean las creencias de las víctimas o de quienes hayan sobrevivido a las víctimas.

Estas exigencias fuertes de verdad provocan que las reconstrucciones históricas que sean llevadas a cabo por los jueces no debieran -en principio- ser instrumentales al logro de ciertos objetivos como es el caso de plea bargaining que implica una renuncia a una reconstrucción fidedigna de la realidad. En comunidades políticamente maduras no resultan satisfactorias las reconstrucciones torcidas de los acontecimientos, aun cuando pudieren en el corto plazo ser útiles para la adecuada gestión, por ejemplo, de las rivalidades pendientes. ${ }^{43}$

La disponibilidad de una historia acerca de acontecimientos especialmente penosos para una comunidad, que pueda llegar a ser reconocida como próxima a la verdad-aun cuando aquélla resulte infame-, se reconoce como valiosa a efectos de reconstruir lazos de fraternidad en una comunidad más o menos amplia. Por cierto, en el caso de las violaciones a los derechos humanos resultan útiles tanto las buenas historias que soportan condenas como las buenas historias que soportan absoluciones. Para tales efectos, los estándares de prueba civil y penal no parecen ser especialmente satisfactorios. Si bien es cierto aquél que rige en el ámbito penal es exigente ${ }^{44}$ para la construcción de buenas historias de culpabilidad del condenado, resulta de poca utilidad para la construcción de historias de inocencia sobre quien ha sido absuelto. En los casos civiles, si bien es cierto no hay -como ha sido dicho- un tratamiento asimétrico entre el demandado sobre el que se impone una carga y el demandado al que se ha exonerado de la obligación pretendida, las historias construidas para cualquiera de esos casos pudieren llegar a ser demasiado débiles como para configurarse como una reconstrucción de la realidad que satisfaga las pretensiones del auditorio al que podría dirigirse una sentencia que resuelva una causa de violación por derechos humanos.

El estándar de prueba de la preferencia de las buenas explicaciones no derrotadas constituiría una propuesta que podría ser apta para hacerse cargo, por una parte, de que para efectos de construir buenas historias acerca de episodios de vulneración de derechos humanos se precisa disponer de una cantidad elevada de información y de análisis acucioso de ésta y, por la otra, de una gestión del potencial error en que pudiere incurrirse que no impida que buenas explicaciones resulten vencidas por historias mediocres, aun cuando pudieren alcanzar visos de plausibilidad.

En cuanto a la cantidad de la información que sería requerida según el estándar de prueba propuesto, es útil advertir que al indicarse que debe tratarse de a lo menos una

\footnotetext{
${ }^{43}$ El caso probablemente más notable al respecto podría ser el del famoso Edicto de Nantes que llamó a asumir las guerras de la religión en Francia "como cosa no sucedida”.

${ }^{44}$ Esto, por cierto, dependiendo de la interpretación que sobre él se haga valer. Cfr. Laudan, L. Truth, error and Criminal Law. Cambridge University Press, Cambridge UK, 2006, p. 32 y ss. En el caso chileno ver Accatino, D. "La fundamentación de la declaración de hechos probados en el nuevo proceso penal: Un diagnóstico", en Revista de Derecho de la Universidad Austral, Vol. XIX, No 2, diciembre 2006, pp. 20-21.
} 
buena explicación se está imponiendo sobre el acusador la exigencia de producir prueba suficiente -habida cuenta del background de conocimientos del auditorio al cual se pretende hablar- como para vencer las resistencias iniciales que traería aparejada la aceptación de cualquier historia construida con pretensiones de representar la realidad. Así, por ejemplo, si se pudiere reforzar la historia propuesta el disponer de exámenes de ADN, de peritajes o de prueba de testigos $-\mathrm{y}$ todas ellas pudieran llegar a ser presentadas en la audiencia de prueba sin tener que incurrir en costos exagerados-, el hecho de que no se cuente con ellas debiera constituir una razón poderosa para que se entienda que el estándar de prueba no ha sido plenamente superado. Las buenas explicaciones también implican un adecuado nivel de teorización en cuanto a que si se tiene en cuenta toda la prueba producida en la audiencia respectiva, se contaría con buenas razones como para que a partir de ella sea dable inferir que aquello que se dice que habría ocurrido conforme a la historia de cargo haya efectivamente acontecido. Esto, por cierto, implica un análisis minucioso desde el punto de vista de la coherencia de la historia, de su fidelidad con los datos que le sirven de soporte, de la exclusión de hipótesis ad hoc, etc.

Como se habrá advertido, hasta aquí no habría grandes diferencias del estándar de prueba propuesto con el del "más allá de toda duda razonable", pues la eliminación del género de dudas que aquel implica supone un esfuerzo de producción y de análisis de información similar a aquel que hasta este momento sería exigible. Las discrepancias se producirán en lo que respecta a la forma de distribución del error. Como podrá haber sido inferido de lo dicho hasta ahora, la exigencia de buenas explicaciones constituye un mecanismo apto para eliminar errores gruesos que podrían producirse en los casos de falta de información relevante para la toma de una buena decisión, lo que sí sería posible que ocurriese en casos civiles. Es decir, los errores que serán distribuidos entre el acusado y el acusador son aquéllos más sutiles, esto es, aquellos en que, incluso, un analista minucioso y agudo podría incurrir, pese a contar con información de buena calidad. La distribución de estos potenciales errores en una forma asimétrica entre las partes, si bien protegerán a una de ellas que se entiende como más débil, incidirá en que habrá un mayor número de equivocaciones que las que serían esperables si se llegasen a distribuir simétricamente.

Para explicar lo recién señalado me valdré del siguiente ejemplo. Imaginemos que Brett juega una partida de póker con sus amigos y al momento de colocar sobre la mesa sus cartas, una de ellas sale volando debido a una fuerte ráfaga de viento que penetra por una ventana que había sido abierta para capear el calor. Luego de exhibirse las cartas en poder de los demás jugadores se concluye que si Brett hubiese tenido un diez (que es, precisamente, lo que él sostiene aun cuando no recuerda de qué pinta) habría ganado la partida; en caso contrario, la habría perdido. Anabelle es designada como la persona encargada de recoger del suelo la carta perdida y se encuentra con la sorpresa que también volaron hasta allí otras tres cartas del mazo, las que son imposibles de distinguir de aquélla que portaba Brett. Las cuatro cartas en el suelo eran 10 de diamante, 10 de corazón, 10 de trébol y 8 de diamante. Por cierto, que podría entenderse que habría una duda razonable en cuanto a que la carta 
que perdió Brett era efectivamente un 10, ya que también había un 8; sin embargo, si se resolviese que no está demostrado que Brett tenía un 10 en su mano implicaría que se estaría asumiendo un riesgo mucho mayor de equivocación en comparación con el que se produciría si se diere por probado que la carta que Brett extravió era un 10 (incluso si asumimos la declaración inicial de Brett como irrelevante).

Cada vez que se desecha una buena historia del acusador, en razón de que subsiste una duda razonable de que aquélla podría no ser cierta, podría estar renunciándose a una buena historia. Que ello ocurra en casos penales ordinarios no parece una mala cosa, pues es el precio que estamos dispuestos a pagar porque un inocente no llegue a ser castigado. Sin embargo, si se trata de un caso seguido por violación a los derechos humanos la renuncia a una buena historia (que eventualmente podría incidir en la condena de un inocente), es bastante más difícil de aceptar en razón de que -como ha sido dicho- la función de construcción de historias es en este contexto de elevada importancia.

Podría objetarse el debilitamiento de la posición del acusado en cuanto sujeto legitimado para falsar la historia presentada por el acusador. Ello estaría asociado a cierta posible insatisfacción en las víctimas de las violaciones a los derechos humanos quienes esperan que la justicia sea hecha con todas las garantías de un debido proceso. Al respecto quisiera precisar lo siguiente: i) los estándares de prueba según se ha dicho son mecanismos para distribuir el posible error en el que podremos incurrir en razón de la incertidumbre respecto a qué es lo que habría sucedido; ii) en estricto rigor, todo estándar de prueba que se fije bajo la línea de la certeza estará admitiendo que ocasionalmente se condenará a inocentes (es el triste precio que debemos pagar para que el sistema funcione); iii) si se fija un estándar de prueba como el sugerido, el respeto al debido proceso no tambalea, por cuanto al igual que como ocurre con cualquier estándar es el producto de una reflexión moral o política (en todo caso sigue siendo exigente); iv) en los juicios por violaciones a los derechos humanos no se produciría con la misma fuerza el problema de asimetría en cuanto a la posibilidad de producir prueba, como sí ocurriría en casos penales ordinarios. Recordemos que el agente que ha violado los derechos humanos contó, en su momento, con la complicidad de un aparato estatal, lo que muchas veces posibilitó la destrucción de registros y, en general, de muchos rastros, lo que, con frecuencia, lleva a investigaciones especialmente dificultosas. ${ }^{45}$

${ }^{45}$ Para la fuerza de este contraargumento, por supuesto, se está pensando que un aspecto distintivo de las violaciones a los derechos humanos lo constituye el hecho de que las prácticas de tortura, desaparición forzada o similares hayan sido ejecutadas por agentes del Estado. En el caso del Informe de la Comisión de Verdad y Reconciliación que fue constituida en Chile el año 1990 se optó por no restringir el concepto de violación a los derechos humanos a los cometidos por agentes del Estado, siendo una razón fuerte para ello el que en el decreto de su creación así había sido estipulado. Sin perjuicio de ello, en el mismo informe se plantea que una perspectiva amplia es problemática diciéndose, por ejemplo, que “...no se desconoce que los particulares también pueden atentar contra la vida, o contra otros importantes valores, pero tales atentados se pueden calificar apropiadamente de crímenes, de actos de terrorismo, o bien de otra manera, según sea el 
Cuando se absuelve en razón de que la buena historia del acusador ha sido derrotada por otra igualmente buena, o incluso mejor, no estamos renunciando al rol de los jueces de colaborar en la construcción de nuestras representaciones del mundo en ciertos asuntos de alto impacto; a contrario, estamos con ello presentando una explicación apta para reivindicar a quienes han sido acusados de cometerlas sin una suficiente justificación.

Antes de concluir, quisiera hacerme cargo brevemente de una afirmación realizada al inicio de este trabajo en cuanto a que el estándar de prueba que aquí ha sido propuesto sería aplicable también a las implicaciones civiles que pudieren asociarse a las violaciones a los derechos humanos. La aceptación en un sistema jurídico del estándar de prueba de la preferencia de las buenas explicaciones no derrotadas traería consigo una mayor dificultad para acoger pretensiones civiles en este tipo de asuntos, esto es, implicaría un endurecimiento de la desventaja inicial de la que debe hacerse cargo el demandante. Creo que este planteamiento hace no perder coherencia a la hipótesis planteada relativa a la importancia de la verdad en los casos de violaciones a los derechos humanos. Sencillamente no se vería por qué, si de lo que se trata es tanto construir historias como aplicar cargas sobre los culpables, pudiera ser razonable hacer diferenciaciones dependiendo de los bienes que estén en juego. Probablemente, en este tipo de asuntos produciría mucha desazón el advertir que una determinada reconstrucción de la realidad ha sido considerada plausible en un contexto y en otro, no. Una historia así, francamente no podría llegar a constituirse como una representación satisfactoria de la realidad.

Nuestras reconstrucciones de la realidad sólo quedarán abiertas si ninguna de las partes hubiere sido capaz de presentar una representación de la realidad digna de ser tenida en consideración. En esos casos y si el problema sigue afligiéndonos como sociedad, corresponderá a otros (historiadores, periodistas, etc.) llegar a mostrarnos los episodios pasados de una manera ojalá próxima a tal como ocurrieron. Ese será, probablemente, el caso de no pocos dictadores y de altos mandos a los que una fuga insidiosa o una vida no suficientemente larga se confabularon impidiendo que un enjuiciamiento bien llevado narrase su verdadera bistoria.

\section{BIBLIOGRAFÍA}

Accatino, D. "La fundamentación de la declaración de hechos probados en el nuevo proceso penal: Un diagnóstico", en Revista de Derecho de la Universidad Austral, Vol. XIX, No 2, diciembre 2006.

Alchourrón, C.; Bulygin, E. "Los límites de la lógica y el razonamiento jurídico”, en ID. Análisis lógico y derecho. Centro de Estudios Constitucionales, Madrid, 1991.

caso. Llamarlos "violaciones de derechos humanos" desvía la atención sobre la gravedad especial que tiene el hecho de que el Estado, que detenta la fuerza pública y está encargado de proteger los derechos de los ciudadanos, emplee tal fuerza para violarlos”. El informe está disponible en www.lanacion.cl/custom/rettig/ informe_rettig.doc 
Anderson, T.; Twining, W. Analysis of evidence. How to do things with facts. Weidenfeld and Nicolson, London, 1991.

Austin, J. L. Palabras y acciones. Cómo hacer cosas con palabras. $1^{\text {a }}$ ed. Paidós, Buenos Aires, 1971.

Berger, P.; Luckman, Th. La construcción social de la realidad. 26 reimpresión. Amorrortu, Buenos Aires - Madrid, 2006.

Celano, B. "Judicial decision and truth. Some remarks", en Gianformaggio, Letizia; Paulson, Stanley. Cognition and Interpretation of Law. G. Giappichelli, Torino, 1995.

Cohen, L. J. "Belief and acceptance", en Mind, vol. XCVIII, 1989.

DAMAŠKa, M. "Truth in adjudication”, en Hastings Law Journal 49, 1998.

ELSTER, J. Juicios salomónicos. Las limitaciones de la racionalidad como principio de decisión. $1^{\text {a }}$ edición. Gedisa, Barcelona, 1991.

HAACK, Susan. "Truth and Justice, Inquiry and Advocacy, Science and Law", en Ratio Juris, vol. 17, $\mathrm{N}^{\circ}$ 1, March 2004.

Hart, H.L.A. El concepto de derecho. $2^{\mathrm{a}}$ ed. Abeledo-Perrot, Buenos Aires, 1977.

Kelsen, H. Teoría pura del derecho. 9a ed. Porrúa, México D. F., 1997.

Kunn, Th. "Comentarios sobre las relaciones de la ciencia con el arte", en ID. La tensión esencial. Estudios selectos sobre la tradición y el cambio en el ámbito de la ciencia. Fondo de Cultura Económica, Madrid, 1993.

Laplace, P. S. Ensayo filosófico sobre las probabilidades. Espasa-Calpe, Buenos Aires, 1947.

LAUDAN, L. "Por qué un estándar de prueba subjetivo y ambiguo no es un estándar", en DOXA 28 (2005).

Laudan, L. Truth, error and Criminal Law. Cambridge University Press, Cambridge UK, 2006.

MÁrai, S. El último encuentro. Salamandra, Barcelona, 1999.

Nietzsche, F. Sobre verdad y mentira. Miluno, Buenos Aires, 2008.

Posner, R. "An Economic Approach to the Law of Evidence”, en 51 Stanford Law Review (19981999).

Ricoeur, P. La memoria, la historia, el olvido. $2^{\mathrm{a}}$ ed. Fondo de Cultura Económica, Buenos Aires, 2008.

Ross, Alf. Auge y Decadencia de las Expresiones Realizativas (1974), p. 187. Disponible en http:// www.juridicas.unam.mx/publica/librev/rev/boletin/cont/21/est/est11.pdf.

SCHAuer, F. Profiles, probabilities and stereotypes. The Belknap Press of Harvard University Press, Cambridge \& London, 2003.

Simon, R.; Mahan, L. "Quantifying burdens of proof. A view from the bench, the jury and the classroom”, en Law and Society Review, February 1971,

TARuffo, M. ¿Verdad negociada?, en Revista de Derecho de la Universidad Austral de Chile, Vol. XXI, $\mathrm{N}^{\circ}$ 1, julio de 2008,

Tyler, T. Why people obey the Law. Yale University Press, New Haven-London, 1990, 
